\title{
LES FONTS ORIENTALS \\ DE LA HISTÒRIA DE JACOB XALABIN
}

Per

LLÚCIA MARTINN PASCUAL

La Història de Jacob Xalabín és una novel.la curta catalana que presenta I'atractiu d'aproximar-nos a la Cort Otomana de finals del segle XIV. El tema central l'ocupa la figura del príncep Jacob, fill del soldà Murat I (regnà de 1360 a 1389), al voltant del qual es va crear una llegenda arran de la seua mort, víctima del seu germà Bajacet, en un acte fratricida, temerós aquest per la popularitat que havia assolit Jacob després de la batalla de Kossovo contra els cristians serbis (1).

La novel.la catalana conta aquest episodi com a col.lofó de la història episòdica central que protagonitza el príncep Jacob Xalabín. Aquest títol que significa "L'Honorable" era propi dels hereus al tron (2). D'altres personatges pertanyents al reialme otomà i presents a la novel.la són l'emir Murat (I'Amorat de la novel.la) i Bajacet (Beseyt Bey a l'obra) que només apareix als capítols finals i té la missió de donar mort al protagonista. Tots els altres, amb la possible excepció d'Alí Baxà (3), són producte de la ficció que va provocar la literaturització d'uns fets llunyans que curiosament es reflectiren en una obra catalana.

La primera impressió que va a provocar la nostra novel.la als investigadors va ser la d'un relat històric, contava amb fidelitat episodis de la Cort Oto-

(1) Veg. A. D. Alderson, The structure of Ottoman Dinasty, Oxford, 1956, pàg 26.

(2) Ibia, pàg. 113 .

(3) Veg. L. Brehier, El mundo Bizantino. Vida y muerte de Bizancio. Mèxic, 1956, pàg. 412. 
mana. Es va donar massa importància a la base històrica sense dedicar atenció al fet literari en ell mateix (4).

El primer estudiós que es va adonar de la important base contística oriental que hi ha a la novel.la, va ser Sigfred Bosch (5), el qual fa un esboc de les fonts orientals com a apendix de les fonts orientals del Tirant lo Blanc, associant les dues novel.les dins el gènere cavalleresc $i$ les influències que el gènere va tenir de la cavalleresca àrab.

Bosch se centra a aquelles novel.les de les Mil i Una Nit que ha trobat poden tenir un fons semblant a les novel.les catalanes. Concretament estableix relació entre el Jacob Xalabín i les narracions «Història de Qamar az-Zaman i la princesa Budur» i també "Història de Baibars i l'onzé capità de policia» (6). El tema més rellevant d'aquests dos contes orientals, sobretot del segon, és el de la madrastra que s'enamora del seu fillastre i en veure's rebutjada planeja la mort del jove. Es, en definitiva, el tema de la primera part de la novel.la catalana (capítols I-IV) i que provoca la desgràcia del protagonista, el qual ha de lluitar per reeixir i recuperar l'equilibri inicial.

Començarem per relatar l'argument de la primera part de la novel.la, per altra banda la que major quantitat d'elements presenta per al nostre estudi. L'estructura de la novel.la catalana en general, es compon de diferents episodis units per un fil narratiu relativament feble, enllaçant-los per formar la totalitat del relat, encara que, a vegades, no semblen massa coherents (7).

L'episodi inicial recull, com hem dit abans, el tema de la madrastra. L'argument és el següent:

A la Cort Otomana viu l'Amorat amb el seu fill «lledesme» Jacob i la seua dona, la jove Issa Xalabina, "la qual era fembra molt jova e de linatge de grechs..., e com cella qui continuament stava en grans balls e solassos així com a dona de gran stament se pertany" (8). Aquesta dona s'enamora del jove príncep i li ho declara directament demanant siga acomplit el seu desig. Jacob "vehen la mala volentat desordonada de la sua madrastra" (pàg 54), fuig de la cort i es refugia en el camp amb el seu amic Alí Baxà, fill del "prohom» Alí Baxà.

E açò feya Jacob Xalabín per tal que's lunyàs de la dita madrastra, la qual veya molt folla e desvergonyada. Perquè ell, volent gordar la honor

(4) Veg. A. Pacheco (ed.) Història de Jacob Xalabín, Barcelona, 1964, pp. 5-7 de la introducció on recull les opinions dels estudis que s'han fet anteriorment

(5) S. Bosch, "Les fonts orientals del Tirant lo Blanc», dins Estudis Romànics II, 1949-1950, pp 1-48. Les pàgines dedicades al Jacob Xalabín són de la 45 a la 48 .

(6) Ibid, pàg 46 .

(7) L'episodi final sembla afegit, encara que algunes opinions diuen que no, perquè s'anuncia des de l'encapçalament. Cfr. Lola Badia, (ed.) Història de Jacob Xalabín, Barcelona, 1982, pàg 20.

18) Les cites són de l'edició de Pacheco de 1964. Aquesta concretament es troba a la pàgina 52. 
de son pare, segons que's pertanyhia a fill, lunyava's aytant con més podia que no li fos denant (pàg 56).

La madrastra, per l'absència de l'objecte del seu amor, emmalalteix sense que ningú puga saber la causa. L'Amorat tem per la vida de la seua estimada dona i mana cridar tots els metges dels Regnes veïns, prometent honors a aquell que puga guarir la dona. Per fí arriba un metge jueu, «qui havia nom en greguesch Quir Mossé» (pág. 59). Aquest es guanya la confiança de la dona que acaba confessant la seua passió. El dolent jueu intenta fer-se amb la voluntat del príncep per tal que aquest accedeixca a jaure amb la madrastra. El príncep es nega tractant el metge de traidor. Aquest no es dóna per vençut i pensa com donarà mort a Jacob. Tot seguit expon a l'Amorat una curiosa explicació médico-sexual de la malaltia i que només guarirà si pren "lo fetge vostro o de vostro fill, que lo vostro e lo seu és tot hu» (pàg 69). L'Amorat mana matar el seu fill després de reflexionar i recolzar-se en un loch de l'Evangeli de Sant Matheu que diu: 'pare e mare e fill jaquiràs per ta companyia" (pàg. 70). El visir Alí Baxà, sense explicar-se el cas és l'encarregat de matar el príncep, però quan és a punt de cometre el crim, el seu fill, Alí Baxà li proposa matar una "grossa cérvia" i presentar el fetge de l'animal en lloc del del príncep. Amb açò finalitza l'episodi, després que a la Cort la dona guareix i el príncep Jacob amb Alí Baxà fuig precipitadament i inicien un procés de pelegrinatge per terres turques.

Trobem a aquest episodi inicial, a banda del motiu universal de la dona que busca l'amor d'un jove, altres dos motius també considerats folklòrics i presents a gran quantitat de manifestacions literàries de diverses cultures; per una banda tenim el conte "del fetge menjat", probablement d'arrels importants en la cultura semítica. El segon motiu identificable és el de la salvació de l'heroi gràcies a la pietat dels botxins, que passa, com veurem a altres novel.letes curtes catalanes.

\section{Origen i difusió del tema de la madrastra}

Es molt difícil desxifrar l'origen d'aquest motiu, present per tot arreu dels relats folkflòrics. El que sí podem veure és la seua difusió.

El relat bíblic de Josep i la dona de Putifar ja ens el presenta (Génesis, 39, versicles 7-15). Conta el moment de I'arribada a Egipte i Josep és adoptat per Putifar, la dona del qual s'enamora i el pretén, però el jove la rebutja. Com a venjança la dona l'acusa i el jove és enviat a presó.

Les històries bíbliques sovint es veuen enriquides per episodis i rondalles agafades de la tradició popular. Aquest pot ser una mostra. Concretament hi ha un conte egipci que no coneixem però s'ha documentat pel 1200 a. de C., titulat, Els dos germans, on es desenvolupa el tema que ens ocupa (9).

(9) Veg. M. Rosa Lida, El cuento popular y otros ensayos, Buenos Aires, 1976, pàg. 17. 


\section{Tradició corànica:}

El Corà recull la història de Josep (sura XII, aleies 21-34) convertint-se un relat de gran popularitat i considerat com "el més bell de tots els relats" (10). Ací Josep és presentat com a model de bellesa, que inevitablement fa que les dones queden admirades en contemplar-lo.

Com a exemple de la popularitat que va gaudir, tenim una llegenda trobada a un manuscrit aljamiat de mitjans del segle XVI (11), titulada Leyenda de José, hijo de Jacob. La llegenda exagera l'episodi dels amors de la dona del rei Alaziz, Zelija, per Josep i recrea la descripció de la bellesa del jove, ací, Josep és a punt de caure en la temptació però s'aparta a temps. L'incident provoca la fugida del protagonista i després d'una sèrie d'esdeveniments té un final insòlit: el matrimoni de Josep i Zelija. En cap versió s'arriba a la unió dels protagonistes. Constitueix, no cal dir-ho, un relat bellíssim.

\section{Les Mil i Una Nit i contística oriental:}

Com ja hem esmentat abans, al corpus literari de les Mil i Una Nit hi ha dos relats que venen relacionant-se tradicionalment amb la novel.la catalana (12).

Començarem per l'argument de la "Història de Baibars i l'onzè capità de policia» (nits 952-3).

El fill d'un soldà té un poltre naixcut el mateix dia que ell i amb la facultat de parlar i previndre el seu amo dels perills. El soldà queda vidu i pren com a muller una esclava del palau que té relacions amb un dolent metge jueu. Per tal que el fillastre no se $n^{\prime}$ adone de les relacions que manté, la madrastra intenta enverinar-lo però gràcies al poltre, no mor. Després la dona es fingeix . malalta i el jueu diu que només guarirà si menja el cor d'un determinat poltre. El jove príncep fuig amb l'animal a una altra cort o es fa passar per pobre. La filla del rei d'aquella cort $s^{\prime}$ enamcra d'ell i el pren per marit. Després de les noces el jove es dóna a conéixer, torna al seu país i pren venjança de la madrastra.

L'estructura d'aquest conte és prou semblant a la de la novel.la catalana, encara que no es dóna la pretensió de la dona vers el seu fillastre. Té altres concomitàncies com la presència del jueu, la malaltia fingida i el guari-

(10) El Corán, traducción de Julio Cortés, Madrid, 1986, pàg 295.

(11) Levenda de José, hijo de Jacob y de Alejandro Dulcarán, sacadas de dos manuscritos moricos del siglo $\mathrm{XVI}$ por F. Guillén Robles de la Biblioteca de Zaragoza, Zaragoza, 1888.

(12) Veg. més amunt l'aportació de S. Bosch, art cit., pp. 45-48, seguida per Pacheco, ed. cit., pàg. 32-33, i per J. M. Solà-Solé, "El Jacob Xalabín i el món àrab", dins Catalan Studies. Volumen in memory of Josephine de Boer, Barcelona, 1977, pp. 213-222.

(13) Nits 170-230. Veg. Joan Vernet, «Las Mil y Una Noches y su influencia en la novelística medieval española», Brable, XXXVIII, Barcelona, 1959-60, pp. 1-21. 
ment amb una víscera, ací d'animal, però de característiques humanes. També coincideix que els dos protagonistes fugen a una altra Cort, es fa passar per pobres i una princesa es fixa en ells. Totes aquestes coincidències poden ser fruit de la difusió oral del conte per Occident, on per la seua singularitat, serviria de base a altres relatsi novel.letes.

La segona narració de les Mil i Una Nit que ens ocupa és la Història de Qamar az-Zaman i la princesa Budur. Té un argument prou complex, a més, és una narració prou difosa i antiga dins la col.lecció oriental (13).

\section{L'argument és el següent:}

El rei Shahraman no aconsegueix tenir descendència fins edat avançada, quan li naix el príncep Qamar az-Zaman. Una vegada el príncep és en edat de prendre muller, rebutja qualsevol contacte que el faja prendre la castedat. La princesa Budur, fitla del rei Ghayur és en el mateix cas que Qamar. Per obra d'uns efrits (genis), els dos joves es troben una nit en una torre, però no arriben a lliurar-se a l'amor. Els efrits tornen a separar-los i ambdós inicien un viatge per tal de retrobar-se. Budur es vist d'home i arriba a una Cort on troba la princesa Hayatu-n-Nufús, el pare de la qual accedeix que es case amb aquella que creu un home. Després d'una sèrie d'averıtures, Qamar Az-Zaman i Budur es retroben i celebren les noces. Qamar pren també per muller a Hayatu$n-N u f u ́ s$. Ambdues tenen un fill que estimen com si andós foren propis. A causa d'açò cada una acaba enamorant-se del fillastre i pretenen aconseguir-los. Com els joves les rebutgen, els acusen de traidors $i$ els condemnen a mort. El rei mana el seu visir done mort als prínceps i per certificar el crim, porte un vas amb la sang de cadascun. El visir, per pietat, mata un lleó i deixa lliures els germans.

L'estructura d'aquest conte és completament diferent de com es desenvolupa la novel. la catalana. Hi ha algunes concomitàncies que difícilment podrien servir de font.

Sense l'episodi final dels amors de les madrastres, la Història de Qamar az-Zaman va servir de font a una sèrie de novel. les franceses, italianes, així com d'una novel. leta inclosa al recull de Timoneda El Patrañuelo, concretament la patranya $I X$, prova que la contística oriental i aquest relat en particular era ben conegut en Occident (14).

Per finalitzar aquest apartat d'influències de la contística àrab en els capítols inicials del Jacob Xalabín, esmentarem un conte atribuït a Avicena i que forma part d'un altre titulat "L'ídol del rei i la seua filla", que a la seua vegada

(14) Veg. Enrico Cerulli, "ll Patrañuelo de Juan de Timoeda e l'elemento arabo nella novella italiana e spagnola del Rinascimienton, Atti de /'Ácademia dei Lincei, anno CCCLIHI, serie ottava, vol., VIil, Roma, 1956 , pp. $81-100$. 
va ser la font d'una obra filosòfica del segle XII, El Filòsof autodidacta, d'Ibn Tufail, font al seu temps d'una obra de Gracian (15).

El conte a què ens referim té el següent argument:

Salaman i Absal eren germans uterins. La muller de Salaman s'enamora d'Absal que era cast, valent, bell i savi. La dona li declara la seua passió però Absal la rebutja. Llavors la dona va pensar casar la seua germana amb Absal i substituir-la la nit de noces. Absal es va adonar de l'engany i aquest va partir de la Cort a combatre en una guerra. Quan va tornar, va rebutjar de nou la dona del seu germà. Absal torna a la guerra, però els soldats, sobornats per la dolenta dona, l'abandonaren tot nafrat enmig el camp, on s'alimentava dels pits d'una fera. Tornat a casa, la dona l'emmezitnà en complicitat amb un criat. Salaman, consirós, es retira a la vida ascètica on Déu li va revelar la veritat del crim. Llavors, va ordenar que la dona i el criat begueren el mateix verí que Absal i tots van morir.

L'única cosa rellevant d'aquest conte és, una vegada més, la repetició del tema dels enganys de les dones quan es tracta d'assolir un amor prohibit, i també, la mort del protagonista després d'una batalla on ha estat victoriós.

Aquest conte va apareixer en un manuscrit àrab, possiblement del segle XVI. Emilio García Gómez, I'ha estudiat i creu procedia del Xarc AlAndalus (16). Açò és molt probable si pensem que aleshores a València hi havia el major nucli de població musulmana (moriscos) amb una producció literària pròpia. Una altra dada que ens permet arribar a la conclusió que a València es coneixien relats i tradicions musulmanes que influirien en la literatura en Ilengua catalana.

\section{El Sendebar i la seua difusió}

A banda de les tradicions coràniques i la novel.lística àrab, una col.lecció de contes, possiblement d'origen sànscrit i difosa en Europa pels àrabs, té importància per al tema que ens ocupa. Es tracta del Sendebar, que va passar a les traduccions medievals amb diferents títols: Libro de los engaños de las mujeres, Libro de los Siete Sabios, entre d'altres. Els àrabs també inclogueren una versió a les Mil i Una Nit que contribuiria a la seua difusió (17).

El que ens interessa del conjunt és la història-marc: Un rei poderós no aconsegueix tenir fills. Una nit jau amb una favorita després d'invocar la divi-

(15) Veg. Emilio Garcia Gómez, "Un cuento árabe, fuente común de Abentofail y Gracián», Revista de archivos, bibliotecas y museos, año XXX, Madrid, enero-julio, 1926. pp. 17-18.

(16) lbid, pàg. 67. L'estudi complet va de les pàgines 1-67 i $241-260$

(17) Veg. J. Samsó, Antologia de las Mil y Una Noches, Madrid, 1986. Inclou la versió del Sendebar a les nits $570-606$

Veg. també l'estudi de M. Jesús Lacarra, La cuentística medieval en España. Los origenes, Zaragoza, 1979, dedica al Sendebar les págines 22-33. 
nitat i li naix el fill. Quan el jove fa els vint anys un savi pronostica que durant una setmana estarà en perill de mort i li aconsella no parlar mentre dure el perill. Una altra favorita del rei trama una conspiració després que el jove l'ha rebutjat: I'acusa davant son pare dels delictes de conspiració i traició. El rei condemna a mort el seu fill, que no pot defendre's perqué sobre ell és la prohibició de parlar. A partir d'ací, durant set dies, set savis contaran diferents històries per salvar el príncep, la dona fa el mateix també durant els set dies. Els exemples dels savis convencen el rei que perdona el fill i condemna la dona.

No sols a la tradició oriental apareix el motiu que hem anat constatant. També a la tradició greco-llatina hi trobem relats que constituiran tragèdies (recordem Hipòlit).

El tema tingué prou difusió en els exempla medievals, generalment de caràcter misògin. A la literatura catalana cal esmentar l'obra de Llull, el Blanquerna on l'episodi entre Blanquerna i Natana fa recordar el tema de la inducció a l'amor per part de la dona. Llull dona un sentit diví al passatge, que acaba ingressant la dona en una ordre religiosa, convençuda per Blanquerna (18).

Posteriorment, al segle XVI, una de les novel.les del Patrañuelo (la patranya $X X)$ desenvolupa el tema de la madrastra, encara que sembla més bé provinga directament de la tradició greco-llatina (19). No obstant, la relació temàtica és evident.

\section{La malaltia d'amor. El conte del fetge menjat}

Passem ara al segon motiu que apareix a la Història de Jacob Xalabín. Aquest tema, present als tractats de medecina medievals, es va desenvolupar en la novel.la sentimental. La literatura àrab té també novel.les "sentimentals" anteriors a les Mil i Una Nits on els protagonistes moren d'amor (20).

Per guarir la malaltia d'amor, cal a la nostra novel. la, presentar una part del cos de la persona que ha inspirat la passió. Generalment a la rondallística popular el fet de portar una víscera del condemnat serveix per certificar la seua mort (recordem el conte de Blancaneus). D'altres referències literàries ens remonten a la llegenda de Guillem de Cabestany (21), en la qual la dona amant del trobador menja el seu cor per una venjança, que ha tramat el marit.

\footnotetext{
(18) Ramón Llull, Llibre d’Evast e Aloma e son fill Blanquerna, vol. I, cap. 6, pág. 68, Barcelona, 1935.

(19) J. de Timoneda, El Patrañuelo, ed de Federico Ruiz Morcuende, Madrid, 1958, pp. 193-200 (patranya $X X)$. La versió que trobem ací coincideix amb la que trobem a l'obra d'Apuleio, L'ase d'or, veg. I'edició de José M. Royo, Madrid 1985, pp. 245 i següents.

(20) La novel.la sentimental àrab més coneguda és Layla i Mecnun que coneixem per una versió turca feta al segle XVI per Fuzulti. Veg. edició d'aquesta obra per Sulayman Salom, Madrid, 1982.

(21) Es troba al Decameró, IV, novel.la 9 i també al recull // Novellino (possiblement anterior al Decamero), novel.la LXIII. També, no cal dir-ho a la Vida del trobador recopilada per Martí de Riquer, Los trovadores, I, Barcelona, 1975, pág. 1067.
} 
Segons la tradició musulmana i dels pobles semítics, el fetge és la víscera central del cos humà on resideix la vida i sent l'amor (22). Per altra banda se li atribueixen també propietats curatives i màgiques (23).

Les rondalles turques desenvolupen, curiosament, el tema de la utilitat del fetge com a curatiu: quan es tracta de guarir la malaltia d'una princesa boja d'amor, l'únic remei és que menge el fetge de l'estimat (24).

Aquest tema ens ha sobtat per tractar-se d'una peculiaritat de les rondalles turques, la qual cosa ens remet a la possibilitat d'una font directa, que no sols va transmetre l'ambient els noms dels personatges i la llegenda de la batalla final, sinó també un motiu típic del folkolore turc, autèntica novetat en el panorama literari del segle XV.

\section{La salvació de I'heroi}

Per finalitzar donarem unes notes sobre aquest motiu ben representat en la rondallística i del qual ja hem vist a alguns exemples als contes orientals que hem citat (recordeu la part final del de Qamar Az-Zaman, de les Mil i Una Nits). Un altre episodi de les Mil i Una Nit fa refència a aquesta història (nit 12): un nen és condemnat a mort però gràcies a la pietat del botxí se salva, a condició que desaparega del lloc (25).

Hi ha dues novel.letes catalanes que presenten concomitància amb el Jacob Xalabín en aquest tema. Es tracta de les titulades: La Filla de l'Emperador Contastí i La filla del rei d'Hongria (26). Ambdues són versions del mateix tema. La protagonista és condemnada a morir per son pare però la pietat del botxí les salva de la mort, a canvi que no tornen a la Cort, abandonant-les a la seua sort. La primera de les novel.letes es troba al mateix manuscrit que la Història de Jacob Xalabín i la redacció de la qual podria haver estat paral.lela a la de la nostra novel.la.

Fins ací hem fet una constatació dels elements més rellevants que apareixen a la Història de Jacob Xalabín i ens remeten a un origen oriental. Ens hem centrat als capítols inicials on hi és la major part de motius, i a més constitueixen el desencadenant de la posterior narració, que avança veloçment i si bé també conté elements que formen part de la tradició, no els hem trobat

(22) A les Mil i Una Nit, el conte de Oamar Az-Zaman, els amants es criden amb l'expressió «mi hígado».

(23) Encyclopedie de I'Islam, art. de Huseyn G. Yurdaydin, «Kabid», París, 1984, pp. 341-348: «Chez ies arabes, le foie est plutôt blessé par les doleurs que nous appellerions du coeurn, pág. 342. "A côté de la psycho-physiologie populaire... des rudiments de doctrines a base symbolique et magique subsistent pour developper également des conclussions practiques». Pag. 345.

(24) Ibid, pág. 346: "C'est surtout le rol curatif du foie conçu sur le mode de l'efficacité magique qui est mis en relief dans les rares mentions qu'en fait le folklore. Ainsi, dans les contes turques, il est question du foie d'un prince qui seul pourra guerir une princesse folle».

(25) Las Mil y Una Noches, I, edició de R. Casinos Asens, Madrid, 1970, pág. 457.

(26) R. Aramon i Serra (ed.) Novel.letes exemplars, Barcelona, 1934 
tan extesos per novel.les i contes orientals, a excepció de les notes que hem donat quan hem tractat el conte de Baibars i l'onzé capità de policia (27).

De tot açò podem concluir dient que la base tradicional oriental a la novel. la catalana és palesa, que es demostra un coneixement oral d'alguns contes de les Mil i Una Nits i que és sospitós trobar una peculiaritat de les rondalles turques a la nostra novel.la En definitiva el component oral és un tret de la novel.la breu, més bé l'origen d'aquesta, fins que la fixació per escrit frena el procés. Seria aquest també el cas de la nostra novel.la que, a més es veu enriquida per la presència de tots els elements que hem esmentat $i$ els que envoltaren la llegenda de la mort del príncep turc, protagonista d'una novel.la catalana.

(27) De la mateixa manera que al conte oriental, el protagonista de la novel.la catalan a fuig de la Cort de son pare, es fa passar per pobre desconegut, reeix en un fet d'armes que provoca que una princesa s'enamore d'ell i li ho declare trametent-li un objecte, en els dos relats és un mandil o mocador. Els amants poden lliurarse a l'amor dins una torre, concomitància que presenta amb la «Història de Camar Az-Zaman i la princesa Budurn.

Per altra banda, els personatges de la novel.la catalana, Alí Baxà i la germana del senyor de Satàlia mantenen una relació amorosa paral. lela a la dels protagonistes però d'una manera més cómica com correspon a personatges d'inferior rang: recordem el divertit passatge quan Ali disfressat de dona entra en el llit de la germana del senyor de Satàlia. 